\title{
Correction to: Combination of early pushing with extended second stage increases the rates of spontaneous vaginal deliveries, but might be associated with adverse maternal and neonatal outcomes
}

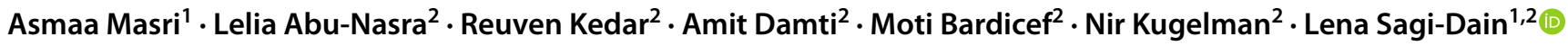 \\ Published online: 10 July 2021 \\ ๑) Springer-Verlag GmbH Germany, part of Springer Nature 2021 \\ Correction to: Archives of Gynecology and Obstetrics \\ https://doi.org/10.1007/s00404-021-06111-w \\ Publisher's Note Springer Nature remains neutral with regard to \\ jurisdictional claims in published maps and institutional affiliations.
}

In the original article published, the given name and family name of all the authors are interchanged.

The correct given name and family name are given below:

Asmaa Masri, Lelia Abu-Nasra, Reuven Kedar, Amit Damti, Moti Bardicef, Nir Kugelman and Lena Sagi-Dain

The original article can be found online at https://doi.org/10.1007/ s00404-021-06111-w.

Lena Sagi-Dain

lena2303@gmail.com

1 The Ruth and Bruce Rappaport Faculty of Medicine, Technion-Israel Institute of Technology, Haifa, Israel

2 Department of Obstetrics and Gynecology, Carmel Medical Center, 7 Michal St, Haifa, Israel 